\title{
UNDERSTANDING SENIORS IN THE CONTEXT OF AN AGING EUROPEAN POPULATION AS A MODIFIER FOR FURTHER BRAND MANAGEMENT: CASE OF THE CZECH REPUBLIC
}

\author{
Olšanová, $\mathbf{K}$.
}

This paper outlines the growing potential of the aging population in Europe with a focus on its impact on the food industry. The importance of mature consumers over the next few decades will radically grow. The impact on companies' volumes will be significant without sophisticated innovations in products and communication. The objective of this paper is to selectively highlight relevant research of the segment of senior consumers and using this to clarify two important areas with significant implications for marketers: (i) the importance of the senior segment for future food marketing and (ii) the specifics of the mature segment in terms of benefits selection for the development of brand positioning strategies. Additionally, different segmentation approaches to the senior market, together with their implications on targeting and communication, are discussed.

JEL Classification: M31

\section{Methodology}

The theoretical framework is divided into two parts. Firstly, statistics are used to highlight the issue of an ageing European population. Secondly, a series of research results is presented in order to study the objective characteristics of seniors as consumers with a special focus on segmentation. Different views on segmentation lead to a problem statement - to what extent is the senior segment heterogeneous in terms of reachability and benefits differentiation? What are the specific factors to be considered when targeting the 50+ market? Conclusions are demonstrated on a virtual example in order to better understand the complexity of the new product development process targeted to the $50+$ market.

\section{Grandparent Boom}

In 1960 in Europe there were, on average, about three young people aged 0-14 years for every elderly person (aged 65 or over); by 2060, there may be more than two elderly people for each youngster. In other words, there are more grandparents for fewer grandchildren than in the past. No matter what the indicator, no country in Europe is projected to have a lower value of seniority in 2060 than in 2010. What is more, the seniors may, on average, outnumber the children of less than five years of age by about the beginning of the next decade. Thus, the presence of great-grandparents may also become more common, and the family more 'vertical' (i.e. multiple generations) than 'horizontal' (more siblings) (Eurostat Population projections - Statistics Explained, 2012). With the extending agedness, children will have grandparents and great-grandparents more frequently than nowadays.

In Europe the population is projected to become older in all Member States, Norway and Switzerland. Thus the median age of the total population is likely to increase in all countries without exception due to the combined effect of the existing structure of the population, persistently low fertility and a continuously increasing number of survivors to higher ages. The ageing process is also visible in the structure of the projected population. The share of the population aged 65 years or over is projected to increase in all countries. It should be noted that in only six countries is the increase projected to be less than 10 percentage points (Giannakouris, 72/2008).

In the Czech Republic, the population is predicted to decrease from the current 10.22 to 8.89 million by 2050 while the amount of population aged $65+$ is predicted to increase from the current 1.58 million to 2.7 million in 2050. Conversely, the population aged 20-64 is predicted 
Figure 1: Population pyramids, EU27, 2008, 2060

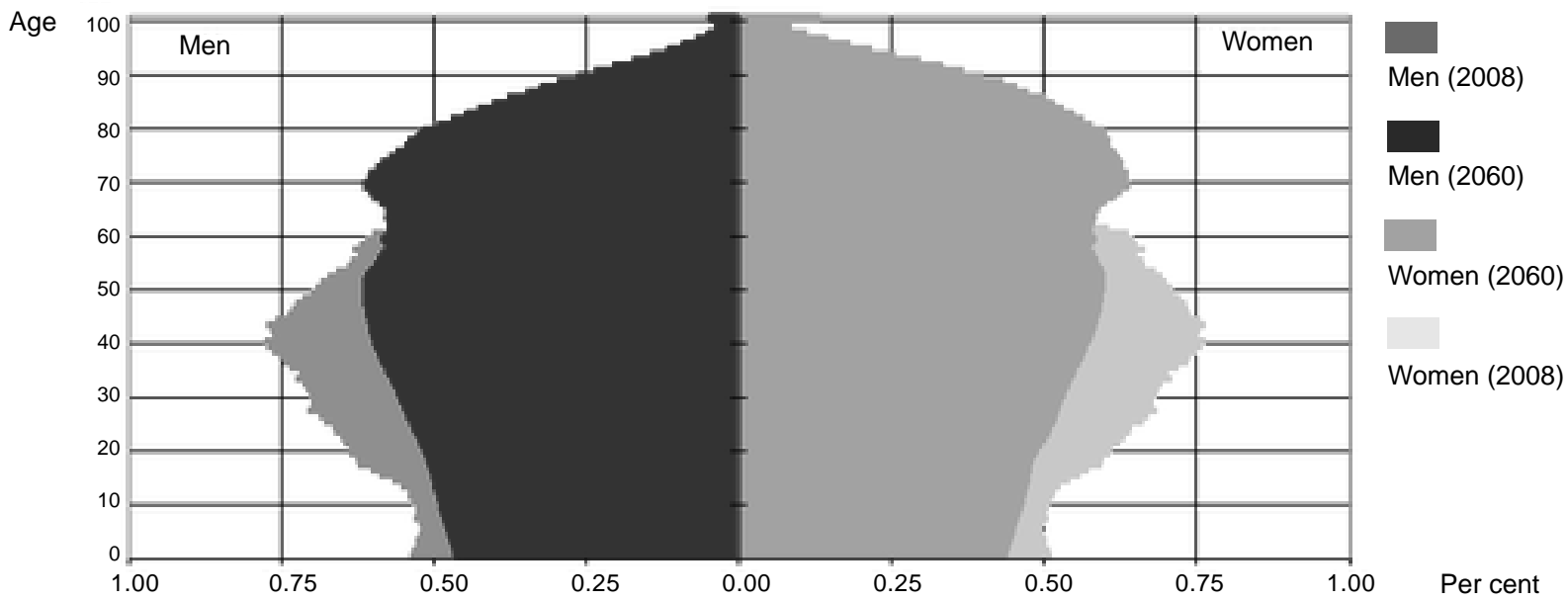

Source: Eurostat, 2012.

to decrease from the current 6.61 million to 4.71 million in 2050, i.e. decrease by 40\%. (Scherbov, Mamolo, \& Lutz). However, there are a few countries where the 20-64 population is projected to grow, e.g. Cyprus, Ireland, Luxembourg and Sweden. Nevertheless, the growth is not significant - the total increase from the mentioned four countries would add up to 0.35 million inhabitants in this age group. In Italy, for example, the population aged $80+$ is foreseen to be $14.3 \%$ of its population in 2050 (compared to current 5.94\%).

Countries neighboring with the Czech Republic do not look optimistic either - total population in three of them is predicted to decline at a double-digit rate (Germany $-11 \%$, Slovakia -15\%, Poland -14\%) while Austria just by -1\%. The population aged 20-64 is predicted to decline in Slovakia at the same rate as in the Czech Republic (-40\%), while the others decline slightly less (Germany -31\%, Poland -38\% and Austria - 18\%) but in absolute numbers those declines are serious. In Central Europe the biggest drop is predicted in Romania, which is supposed to decline from its current 21.4 million inhabitants to 16.7 million in 2050 (- 28\%) and the active part of its population (20-64) is forecasted to decrease by $52 \%$.

Figure 1 demonstrates the ageing EU27 population. The 2008 population pyramid appears more as a rhomboid due to the baby boomer cohorts of the 1960s which are significant on account of their size. Baby boomers will swell the number of the elderly. Thus, this population pyramid for the EU27 shows how the baby boomer bulge is moving up while the middle part (working age population, ages 15-64) and the base (ages 0-14) of the pyramid are projected to narrow considerably by 2060 (Giannakouris, 72/2008).

\section{Evolution of Sophisticated Mature Consumer}

During the 2000-2009 period, in the EU-27 on average, the student population in tertiary education increased by around 22\% (2.7\% annual growth rate), reaching almost 19.5 million individuals in 2009. Future seniors will be more educated with a high proportion of educated women. A third of all 20-22 year olds are in tertiary education, and women outnumber men in almost all EU countries. In 2009, at the EU level, about $13 \%$ of men and $19 \%$ of women aged 18 were participating in tertiary education. Since 2000, the number of female students has increased by almost $10 \%$ with a constant annual rate (EACEA, 2012, p. 79).

Education, combined with the experience brought by age of the mature consumers, is likely to bring many challenges to food producers in terms of product quality, while it may decrease the level of hysteria around product safety as proven by an empirical study where participants were asked to read a short newspaper article about a product crisis (e.g. where it might cause harm) and to respond to a series of questions. The findings indicate that, compared with younger consumers, older consumers perceive these product crises as less threatening, place less blame on the company, and have stronger intentions to purchase and recommend the product involved in the crisis (Silvera, Meyer, \& Laufer, 2012).

\section{Consequences of the Statistical Trends in the Food Industry}

The implications of both an ageing population and an increased level of education include: (i) strong consumer interest in maintaining health and well-being into old age, a focus on specific diets and fit programs, (ii) smaller portions, 
(iii) more user-friendliness for both the labeling (readability) and ease of opening in packaging, (iv) bolder taste profiles, (v) high quality convenience food and eating out more as tertiary educated career oriented women who have children later will be able to afford it (vi) information on food quality, ingredients, additives, traceability and supply chain required by educated consumers, especially women (Hughes, 2009). Moreover, it is likely that those in the educated population will be involved in continuing education throughout their lives and will turn into qualified experienced mature consumers with all of the associated consequences.

The current food offer at retail stores is no longer expected to just fulfill man's basic human needs. The proliferation of choice has resulted for reasons on both the demand and supply side of the chain (Hughes, 2009): (i) increasing consumers' purchasing power on the demand side gives consumers the freedom to specify their food requirements more specifically and sophistically and (ii) on the supply side, food producers and manufacturers active in the mature markets tend to segment the market or food categories in order to allow for volume and margin growth. Product differentiation and adding value are not synonymous terms, and the consumer is the decision maker. His decision, measured by repeat purchase rate, confirms whether real value has been added or just extra costs.

\section{Insightful Understanding of the Mature Consumer Market: Keep a Distance from the Senior Label}

The last decades in food marketing were "a halcyon period of economic growth and, in real terms, declining food prices” (Hughes, 2009). Nowadays, with the upcoming decades of the mature educated consumer, the attributes of convenience, health and well-being, pleasure and more esoteric social elements such as a friendly attitude toward animal welfare, and environmental sustainability (despite its complexities and contradiction with convenience) are increasingly important to consumers in their food choices (Hughes, 2009).

The trickiest part of the innovation process for the mature segment is that the products created and positioned specifically for mature consumers may fail as people do not want to be perceived as those buying senior food or other products connected with a higher age. The exception is medical products and socializing services. In terms of food marketing, the product bundle developed to utilize the opportunity given by the size of the segment should bring the benefits appealing to the senior population without an emphasis on seniority. Fulfilling the needs of this segment is more challenging than that of the younger segments. Seniors will try new products not because it is trendy or because it is the "thing to do" - they will try something if it can meet a personal, specific need they have (Leventhal, 1997). Five age labels (50+, senior, retired, third age and elderly) were explored (Weijters \& Maggie, Evaluation of age-related labels by senior citizens, 2005) in order to find rather positive terms for the senior segment. "Third age" and "elderly" was perceived negatively; "retired” had both positive (a time to enjoy life) and negative (inactive, burden for society) associations. The labels " $50+$ " and "senior" were perceived rather positively, indicating a person that is not so young anymore but is still active. Some respondents though still would not like to be addressed like this in marketing communications or product targeting. The mature consumer does not think of himself as "old” and he does not like to be segmented this way. Older consumers are not likely to appreciate being visibly segmented with their peers. An older person's previous lifestyle is visible on both his/her current physical and psychological person. From this perspective, mature consumers as a group are, by definition, more heterogeneous than younger groups. Fifty-two percent of those aged 55 and above in Europe say their state of health is good while 33\% say it's neither good nor bad and 15\% say it's bad (TNS Opinion \& Social, 2007, p. 5). Their current state of health fundamentally impacts the lifestyle of the mature target group.

The people in charge of brand marketing of the most marketing driven companies are typically young people living in urban areas who have higher incomes and a busy lifestyle. Except for the vision of an enlightened senior management team, there is nothing to motivate them to think about the future of their brands and work on innovations for the mature market - especially as it is a group which is difficult for them to grasp. Here is a list of stereotypes typically used for the senior segment (McGuire, Boyd, \& Tedrick, 2004):

\section{Negative stereotypes of aging}

1. Most older persons are sick or disabled.

2. Most older persons have no sexual activity or desire.

3. Older persons are ugly.

4. Mental abilities start to decline after middle age.

5. Most old persons are "senile."

6. Old workers are not as effective as younger ones.

7. The majority of older persons are socially isolated and lonely.

8. Most older persons live in poverty.

9. Older persons feel miserable (cranky, depressed). 
Figure 2: TNS AISA Segmentation, proportions of $50+$ age group within the lifestyle segments

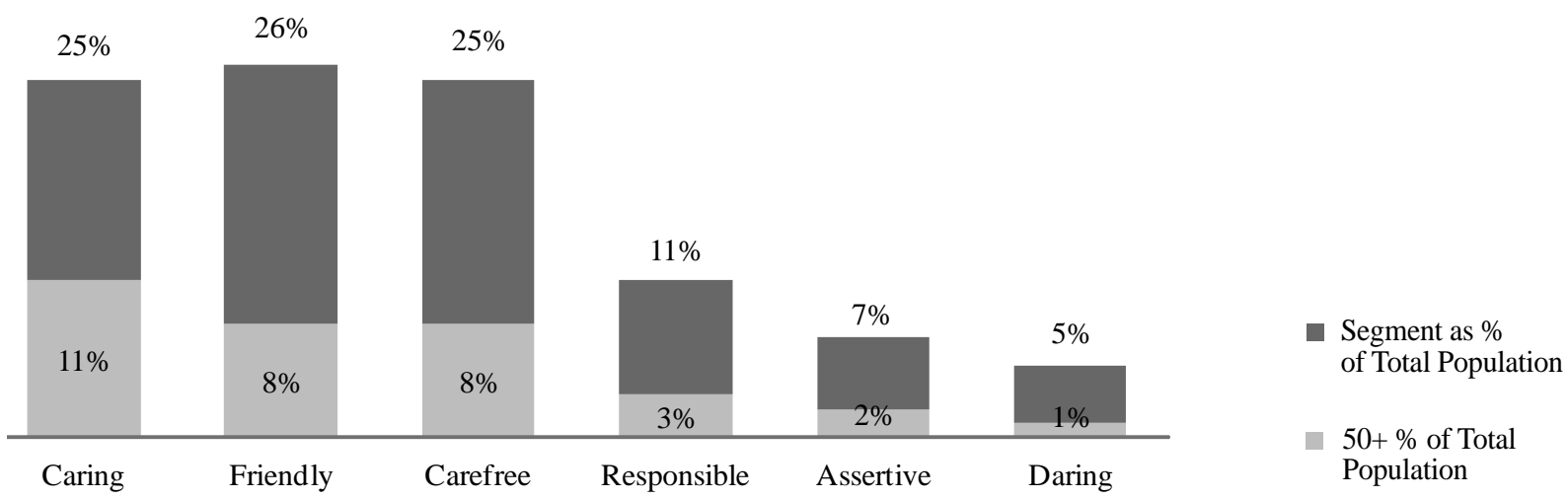

Source: AISA (2011), author's processing.

\section{Positive stereotypes of aging}

1. Older persons are kind and warm.

2. Most older persons have great wisdom.

3. Older persons are more dependable.

4. Older persons are well-off financially.

5. Older persons are a powerful political force.

6. Older persons are free to do whatever they want.

7. It is possible to slow down the aging process.

8. Old age is full of peace and serenity.

When developing and promoting a product for the senior market, it would be a mistake if the marketers advertised products based on false perceptions toward the elderly. Today's seniors are more active and independent than past generations (Dychtwald, 1997), and they are more heterogeneous and difficult to reach. The current stereotypes we have about the senior market should be overcome and new segments of the senior market should be described and targeted.

\section{Segmentation - Recognizing the Heterogeneity of the Mature Consumers' Target Group}

Recognizing and understanding the changes of aging and incorporating this into marketers' decision-making is more likely going to bring success in reaching this target market. A study of the elderly market by Bone revealed the critical segmentation variables of mature consumers; in addition to age, they are: discretionary income, health, level of activity, discretionary time and response to others (Bone, 1991). Socio-economic and demographical data, however, only describe the segments at a general level.
For a better understanding of consumers, companies and researchers work with psychographics and deep lifestyle analyses. In the Czech Republic, TNS AISA mapped the lifestyles of the Czech population through a diary method on a representative sample of ten thousand people (Life Style 2010) (AISA, 2011). This research is continuous (2-year intervals); results from each wave are compared with the previous results. The sample is representative in terms of gender, age (15+), size of residence and level of education. The TNS AISA methodology for mapping lifestyles is limited by scope in that it has two axes - extrovert/introvert and social/individualistic. The segmentation process is based on a battery of lifestyle and attitude questions, which divide the Czech population into the following lifestyle groups: Caring, Friendly, Carefree, Daring, Responsible and the Assertive.

Senior people are exceedingly characterized by the Caring Segment, which describes $25 \%$ of the Czech adult population including $11 \%$ of all seniors, i.e. the $50+$ in the Czech Republic, see Figure 2.

The caring group is characterized by the keywords: peacefulness, reassurance and sensitivity. From the demographics point of view, this segment is largely formed by adults 50+, composed half of women, half of men. People from the Caring Segment are described as: peaceful, serene, gentle, soft, sensitive, caring, nurturing, and reassuring; negative associations with this group are: naive, shy, indecisive, hypersensitive and underestimated. The affinity index describing the proportion of the $50+$ in the segment vs. their proportion in the sample $15+$ is 133 compared to significantly lower indexes in other segments, e.g. representation of the 50+ in others; see Figure 3.

Eighty-one percent of the Czech population aged 50+ belongs in one of the three biggest lifestyle segments (see 
Figure 3: Affinity of 50+ age group within lifestyle segments

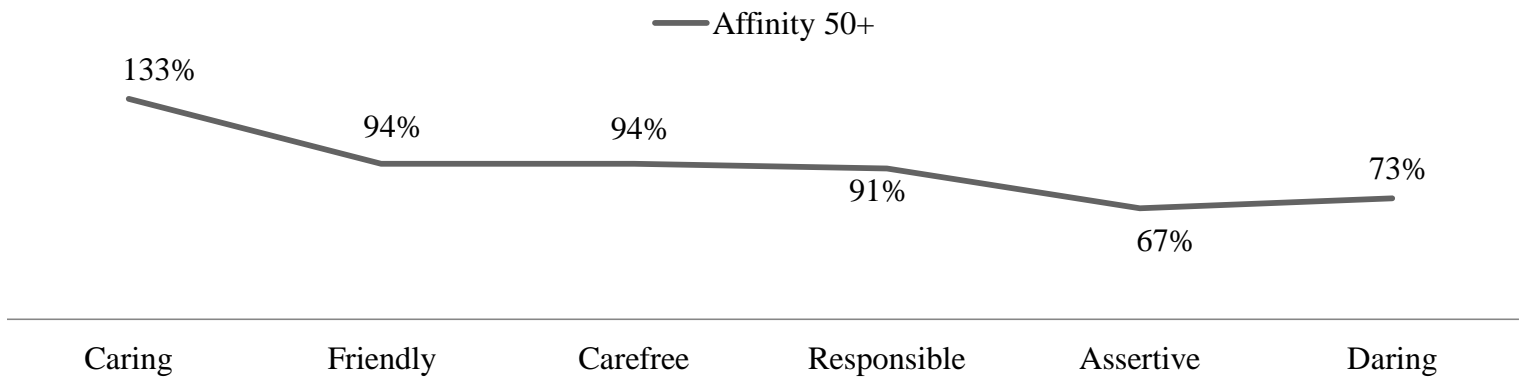

Source: AISA (2011), author's processing.

Figure 4). In the Friendly and Carefree segments, they are proportionally represented as compared to the total population, i.e. the level of their presence is in-line with their representation in the total population. The Caring Segment is over-represented by older consumers ( $50+$ ) by $33 \%$ as is visible from the affinity indexes in Figure 3.

Figure 4: 50+ in lifestyle segments

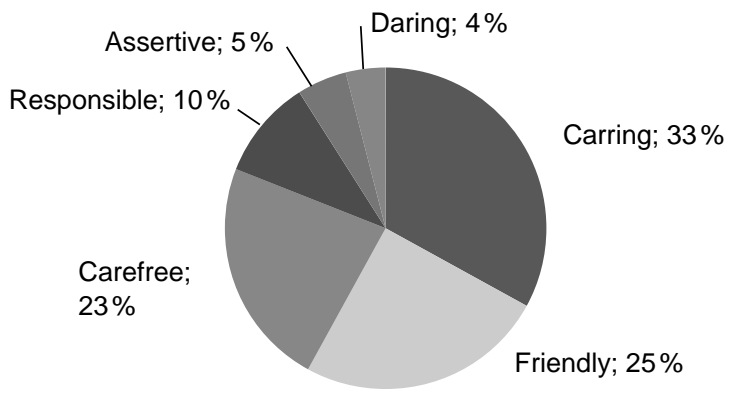

Source: AISA (2011), author's processing.
Comparing the data with the previous wave of AISA research conducted in 2007, the Caring Segment is older (61+), more afraid to remain alone, favors lower prices over quality and more is helpful toward others. They are less interested in the world around them.

AISA recommends some strategies to effectively reach the Caring, Friendly and Carefree Segments; they are summarized in Figure 5. They represent an important set of values to be considered when developing a value proposition targeted to $50+$ people.

These values represent a set of terminal and instrumental values valid for the seniors represented in the three lifestyle segments most relevant for the 50+ population in the Czech Republic.

Leventhal (Leventhal, 1997) summarizes strategies regarding how to reach the mature market while he confirms that there is no magic formula how to win the hearts and minds of aging consumers. His conclusions are supportive of the above AISA segmentation results for the Caring Segment of the Czech population:

Figure 5: Communication to segments representing 50+ people

\begin{tabular}{|c|c|c|}
\hline Caring & Friendly & Carefree \\
\hline 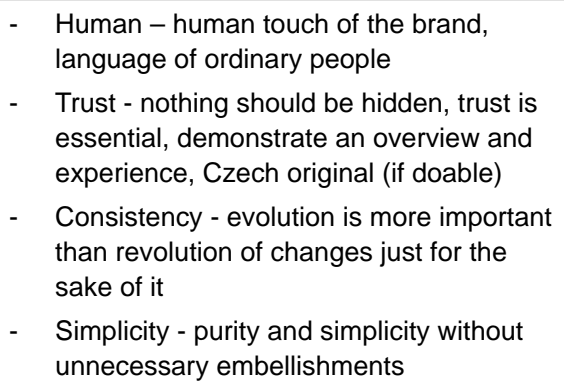 & 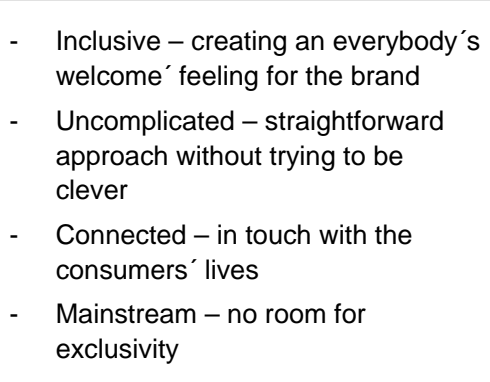 & $\begin{array}{l}\text { - Loud - noisy attention to the } \\
\text { brand on the market } \\
\text { - Engaging - captivating the } \\
\text { consumers, charming them, } \\
\text { being sexy } \\
\text { - Light-hearted - fun, don't take } \\
\text { yourselves too seriously } \\
\text { - Youthful - young at heart }\end{array}$ \\
\hline
\end{tabular}

Source: AISA (2011), author's processing. 
- understand values

- mature consumers are more responsive to emotional stimuli

- mature consumers have an increased demand for facts - tell it like it is

- the older consumer takes more time in making a purchase decision - be patient

- the older consumer is less influenced by peer pressure - objective values are less important

- the older consumer has a strong need to trust a company's product/services - be consistent

- refrain from gimmicks

- keep a sense of humor

- show multigenerational interactions - adding values to other people's choice

- sell the mature consumer in the way they want to be sold - one-to-one relationship

- show the mature consumer in a positive manner

- develop sensitive graphics standards for the older consumer

- treat older people as customers first and as mature customers incidentally

- not all older consumers are created equal

If there is a word to summarize the mature market, it is more likely to be heterogeneity (Moschis, Lee, \& Mathur, Targeting the mature market: opportunities and challenges, 1997) than homogeneity. An alternative approach to segmentation is "Gerontographics" (Moschis, Gerontographics: Life-stage Segmentation for Marketing Strategy Development, 1996, p. 61), i.e. segmentation known as the gerontographics model. Moschis used both gerontological and psychographic variables and divided them into four groups based on psychosocial and biological ageing: (i) healthy indulgers (young on both dimensions), (ii) ailing outgoers (aged just biologically), (iii) healthy hermits (aged just psychosocially) and (iv) frail recluses (aged both psychosocially and biologically). This approach is being contested due to insufficient transparency and clarity (the segmentation cannot be easily replicated nor be easily used by other markets) and because the senior consumers are viewed just as an ageing subject. (Weijters \& Maggie, Evaluation of agerelated labels by senior citizens, 2005).

A study conducted at Ghent University combined two variables - social and professional activity and defined four activity segments: (i) socially active employees, (ii) socially inactive employees, (iii) socially active retirees and (iv) socially inactive retirees (Weijters \& Geuens, Segmenting the Senior Market: Professional and Social Activity Level, 2002). Among retirees, the socially active subgroup is seen as a potentially interesting segment for marketers as they show higher attitudinal brand loyalty, less price sensitivity, have higher discretionary income and are more satisfied with their financial position. Relative to inactive seniors they consider visiting friends, attending courses, practicing sports, and going to culture events as more important (Weijters \& Geuens, Segmenting the Senior Market: Professional and Social Activity Level, 2002).

A study conducted at the University of Massachusetts explored food-related lifestyle segments of the mature market and identified their socio-demographic characteristics in five consumer clusters (Jang, Kim, \& Yang, 2009), see Figure 2.

\section{Benefit Segmentation - Access to 50+ Market}

The methods for segmenting mature consumers are diverse, each balancing specific advantages and drawbacks. The

Figure 6: Food-related lifestyle segments of mature consumers 55+

\begin{tabular}{|c|c|}
\hline $\begin{array}{l}\text { Health- managing } \\
\text { group }\end{array}$ & $\begin{array}{l}\text { - concerned about nutrition, apply nutritional knowledge to their daily life, meals should be prepared } \\
\text { at home } \\
\text { - } 75+, \text { professional, well-educated, upper-income }\end{array}$ \\
\hline $\begin{array}{l}\text { Diet- unconcerned } \\
\text { group }\end{array}$ & $\begin{array}{l}\text { - } \quad \text { indifferent to food and diet } \\
\text { - } \quad \text { not worried about health, nutrition, taste and safety of food } \\
\text { - less educated, with lower disposable income }\end{array}$ \\
\hline $\begin{array}{l}\text { Convenience- oriented } \\
\text { group }\end{array}$ & $\begin{array}{l}\text { - } \quad \text { single, more value on convenience than nutrition } \\
\text { - } \quad \text { taste and safety factors in food-related lifestyle }\end{array}$ \\
\hline Taste-oriented group & $\begin{array}{l}\text { - the youngest (55-64 years), predominantly female, highest income } \\
\text { - } \quad \text { taste is of the utmost importance of their food related lifestyle } \\
\text { - } \quad \text { enjoy cooking, shopping for food and trying new recipes and meals }\end{array}$ \\
\hline Unpracticed group & $\begin{array}{l}\text { - } \quad \text { high health-seeking and safety-seeking lifestyle } \\
\text { - } \quad \text { low importance of taste or balanced diet } \\
\text { - } \quad \text { higher incomes, smaller families }\end{array}$ \\
\hline
\end{tabular}

Source: Jang, Kim and Yang (2009) 
approaches described here are all undoubtedly valid and should be considered by marketers when developing strategies for mature consumers. The technique that R. Ahmad (Ahmad, 2003) proposes for segmentation of older consumers is benefit segmentation, which segments customers on the basis of desired or sought benefits. Ahmad evaluates the advantages of traditional methods of segmenting consumers (e.g. demographic, socio-economic) as well as psychographics, which both have limitations in terms of explaining the reasons why consumers choose to buy or prefer particular products. The benefits, when they are present as attributes of a brand's positioning, cause consumers to purchase those products and should therefore be recommended due to strong correlation with the brand positioning model used for developing profound brand strategies. Benefit segmentation is potentially a powerful technique to identify the wants of older consumers and to segment them into targetable groups and consequently help managers to optimize their limited marketing resources (Ahmad, 2003). The benefits differ in each product category and therefore this is difficult to generalize. Ahmad presents a case of grocery shopping and emphasizes the importance of knowing the traditional profile of older consumers in terms of their demographics/ socioeconomics and lifestyle in order to cluster them into groups based on personal characteristics, which is - at a later stage - confronted with associations between categories of benefits sought. The benefit segmentation approach always uncovers a number of relatively homogenous segments, descriptions of them in terms of averages are much more appropriate and meaningful as marketing guides. Case histories have been notably absent from the literature because most studies have been contracted for the private sector and have been treated confidentially (Haley, 1968). The active use of benefit segmentation together with the passive use of traditional methods of segmentation offers an additional utility - more reliable targeting of older customers. For illustration, I will use the lifestyle segmentation of TNS AISA and their Caring Segment (due to highest affinity with $50+$ consumers) and demonstrate a case of selecting proper benefits for the segment.

Implications for Practice - Positioning for Mature Segments One of the advantages of benefit segmentation is that it is closely linked to brand positioning, which makes it consistent with the brand identity and strategy. Brand positioning is what the product stands for and how it differs from existing and potential competition by designing an identity which clarifies the value of the product. "Selecting an appropriate positioning can make the difference between success and failure. It determines what the organization tells the market about the product, whom it tells and how it tells it"

Figure 7: Relationship in a means-end chain

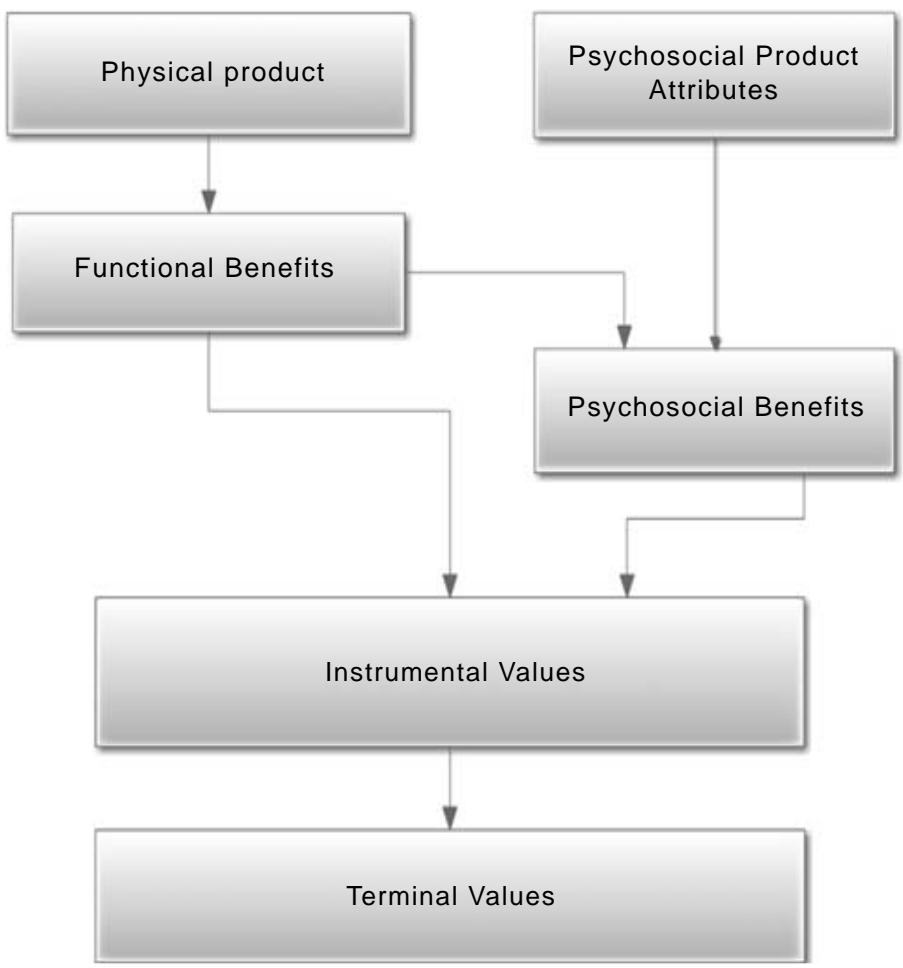

Source: Antonides and Raaij (1998). 
(Trott, 2012, p. 392). The brand positioning model (Keller, Sternthal, \& Tybout, 2002) is focused on how to guide integrated marketing to maximize competitive advantage. A brand positioning statement is formulized via this template: "To (Target Audience) brand X is the brand of (Frame of Reference) that (Brand Promise,) because (Reason Why)". The brand promise, supported by a relevant reason why, creates a brand's point of difference, which must be singleminded, unique, compelling and believable. Brand promise is created based on the set of benefits delivered by the brand and appealing to the consumers as summarized and structured by the benefit ladder. The benefits most appealing and relevant to the target audience create the brand promise, supported by the reason why from one step level lower on the ladder. The target audience's needs influence each part of the positioning statement and are the touch point of each element. Positioning a brand for mature consumers requires open-mindedness from the brand team in terms of avoiding stereotypes of seniors.

The Antonides/Raaij model describes the relationship between physical product characteristics and functional benefits, which leads to fulfillment of the instrumental values and terminal values, see Figure 7. The value proposition - coherent with the model - should offer satisfaction of the consumer needs by offering the best suiting benefits with a view to the values of elderly people.

The relationship between physical product attributes and functional benefits is the primary functionality of the product (Antonides \& Raaij, 1998, p. 144).

I will use the ground coffee segment for illustration of benefit segmentation. I chose typical functional and psychosocial benefits for coffee, which are in-line with the values of the Caring Segment (e.g. consistency, rationality, logic, honesty, sincerity, truthfulness, responsibility):

- expressive taste

- delicious, like a dessert

- brand for everyone

- good quality for a good price

- available everywhere

- traditional brand

- easy to open packaging

The benefit ladder would start with a physical product attribute (= traditional slow way of roasting), product benefit (= expressive taste), consumer benefit (= delicious like a dessert), and an emotional benefit (= pleasurable moments). The emotional benefit is in-line with the values of the Caring Segment and represents the terminal value (pleasure). The terminal values of harmony and happiness could also be considered. Depending on the market structure and competitive analyses, the proper level of benefit would be selected for brand promise supported by reasoning from the lower level. The brand positioning, properly projected not just into the integrated marketing communication but in general to each part of the marketing mix, will ensure effective reach of the senior market segments.

\section{Summary and Managerial Implications}

The objective of this study was to select appropriate recent studies and highlight relevant research regarding the senior consumer segment with special focus on the food industry - and using this - to clarify two important areas with significant implications for marketers: (i) the importance of the senior segment for the future of food marketing, and (ii) specifics of the mature segment in terms of benefit selection for development of brand positioning strategies. In the first part, appropriate data were given highlighting the growing importance of mature consumers as future buyers. The second part focused on presenting different views on segmenting older consumers without the current stereotypes; a special focus on lifestyle segmentation and identification of the most relevant values for the mature market was made. In the last part, the implications were simplified and demonstrated using the Antonides\&Raaij model as an input for the development of brand positioning. This document aims to contribute to a better understanding of the senior market and to bring valuable insights that could be employed in new product development processes within companies.

\section{References}

Ahmad, R. (2003). Benefit segmentation: a potentially useful technique of segmenting and targeting older consumers. International Journal of Market Research , 45 (3): 373-388.

AISA, T. (2011). Lifestyle 2010. Prague: TNS AISA.

Al, R., Trout, J. (2001). Positioning: The Battle for Your Mind. U.S.: McGraw-Hill Companies, Inc.

Antonides, G., Raaij, W. F. (1998). Consumer Behaviour. A European Perspectvie. Chichester: John Wiley\&Sons, Ltd.

Bone, P. F. (1991). Identifying mature segments. Journal of Consumer Marketing , 8 (4): 19-32.

Dychtwald, M. K. (1997). Marketplace 2000: riding the wave of population change. Journal of Consumer Marketing , 14 (4/5), 271-275.

EACEA. (2012). Key data on education in Europe. Education, Audiovisual and Culture Executive Agency. Brussels: Education, Audiovisual and Culture Executive Agency (EACEA P9 Eurydice). 
Eurostat (2012). Population projections - Statistics Explained, (accessed September 24, 2012), [available at http://epp. eurostat.ec.europa.eu/statistics_explained/index.php/ Population_projections\#Main_statistical_findings].

Giannakouris, K. (72/2008). Ageing characterises the demographic perspectives of the European societies. Eurostat. Eurostat.

Haley, R. I. (1968). Benefit segmentation: A decision oriented research tool. Journal of marketing , 32: 30-35.

Hughes, D. (2009). European Food Marketing: Understanding Consumer Wants - The Starting Point in Adding Value to Basic Food Products. EuroChoices, 8 (3): 6-13.

Jang, Y. J., Kim, W. G., Yang, I. S. (2009). Food-Related Lifestyle Segments and Mature Consumers' Attitudes to Home Meal Replacement. International ICHRIE Conference-Refereed Track. Paper 12.

Keller, K. L., Sternthal, B., Tybout, A. (2002, September). Three Questions You Need to Ask About Your Brand. Harvard Business Review, 80 (9): 80-89.

Leventhal, R. C. (1997). Aging consumers and their effects onthe marketplace. Journal of Consumer Marketing , 14 (4): 276-281.

McGuire, F. A., Boyd, R. K., Tedrick, R. E. (2004). Leisure and aging: Ulyssean living in later life (3rd ed.). Champaign, IL: Sagamore Publishing.

Moschis, G. P. (1996). Gerontographics: Life-stage Segmentation for Marketing Strategy Development. USA: Quorum Books.

Moschis, G. P., Lee, E., Mathur, A. (1997). Targeting the mature market: opportunities and challenges. The Journal of Consumer Marketing , 14 (4): 282-293.

Scherbov, S., Mamolo, M., Lutz, W. European Demographic Research Paper: Probabilistic Population Projections for the 27 EU Member States Based on Eurostat Assumptions.
Silvera, D. H., Meyer, T., Laufer, D. (2012, April 29). Age-related reactions to a product harm crisis. The Journal of Consumer Marketing, 29 (4): 302-309.

Tepper, K. (1994). The role of labeling processes in elderly consumers' responses to age segmentation cues. Journal of Consumer Research, 20 (4): 503-519.

TNS Opinion \& Social. (2007). Health in the European Union - Special Eurobarometer No. 272. European Comission. Eurobarometer.

Trott, P. (2012). Innovation Management and New Product Development, 5th edition. Harlow: Pearson Education Limited.

Weijters, B., Geuens, M. (2002). Segmenting the Senior Market: Professional and Social Activity Level. Asia Pacific Advances in Consumer Research , 5: 140-147.

Weijters, B., Maggie, G. (2005). Evaluation of age-related labels by senior citizens. 325. Faculteit Economie en Bedrijfskunde, Gent.

Author

Květa Olšanová

University of Economics, Prague Department of International Trade, Faculty of International Relations

W. Churchill Sq. 4, 13067 Prague 3, Czech Republic kveta.olsanova@vse.cz

This article was written with support of the University of Economics' Internal Grant Agency under project number MF/13/2012. 